\title{
A REVIEW ON THE ANALYTICAL ANALYSIS AND MODELING OF EARTH AIR TUNNEL HEAT EXCHANGER
}

\begin{tabular}{|l|l|}
\hline Jagjit Kaur & Harminder Kaur \\
Department of Mechanical Engineering, & Department of Electronics and Communication Engineering, \\
Guru Nanak Dev Engineering College, Ludhiana, Punjab, & Guru Nanak Dev Engineering College, Ludhiana, Punjab, \\
INDIA. & INDIA. \\
Email: j.jagjeet@ymail.com & Email: harminder12@yahoo.co.in \\
\hline
\end{tabular}

Abstract: Today we primarily use fossil fuels to heat and power our homes. It's convenient to use coal, oil, and natural gas for meeting our energy needs, but we have a limited supply of these fuels on the Earth. We're using them much more rapidly than they are being created. Eventually, they will run out. And because of safety concerns and waste disposal problems it gives globalization problems. Research is carried out in order to increase a share of renewable energy source in the overall task of energy generation. Various research efforts have been rationalized to prove the benefits these could be derived from the utilization of renewable energy for electricity. These sources are currently offered worldwide as an environment friendly which is the major focal advantage. In a developing country like India, there is a huge gap in demand and supply of electricity and rising electricity prices have forced us to look for cheaper and cleaner alternative. Earth air tunnel heat exchangers are simple systems to save energy in buildings. The EATHEs are considered as one of the most passive system due to its ability to provide both the effects; heating in cold months and cooling during warm months. They use the earth's near constant subterranean temperature to warm or cool air for residential, agricultural or industrial used. This paper reviews on the experimental and analytical studies of EATHE systems around the world.

\section{Abbreviations: EATHE earth air tunnel heat exchanger}

Keyword: Fossil fuels Earth air tunnel heat exchanger; renewable energy; passive system

\section{INTRODUCTION}

Energy security and stability are currently the main issues throughout the world. Looking to the energy crisis world over the importance of energy for the existence of our society, it is imperative and urgent to find alternative source to replace conventional fuel or at least mitigate its widespread consumption and consequent impact on the environment. Passive heating or cooling systems are known for their advantage of consuming no or very less energy as compared to the active heating and cooling system. EATHE is one of the most passive system due to its ability to provide both the effects; heating in cold months and cooling during warm months. The thermal capacity of earth is such that the diurnal variations of the surface temperature do not penetrate much deeper than $0.5 \mathrm{~m}$ and seasonal variations up to a depth of about $3 \mathrm{~m}$. Beyond this depth the earth's temperature remains constant. The value of this temperature is usually seen to be equivalent to the all year mean of the soil air temperature of its surface. Therefore at sufficient depth, the ground temperature always higher than that of the outside air in winter and is lower in summer. The earth's thermal potential energy may be exploited using EATHE system.

\section{TYPES OF EARTH}

There are mainly two types of heat exchangers. One is open systems and second is closed systems. In open systems, ambient air passes through tubes buried in the ground for preheating or pre-cooling and then the air is heated or cooled by a conventional air conditioning unit before entering the building.

\section{A. Open system:}

In open systems, ambient air passes through tubes buried in the ground for preheating or pre-cooling and then the air is heated or cooled by a conventional air conditioning unit before entering the building. It has some advantages over others which are; Simple design; lower drilling requirements than closed-loop designs; subject to better thermodynamic performance, typically lowest cost.

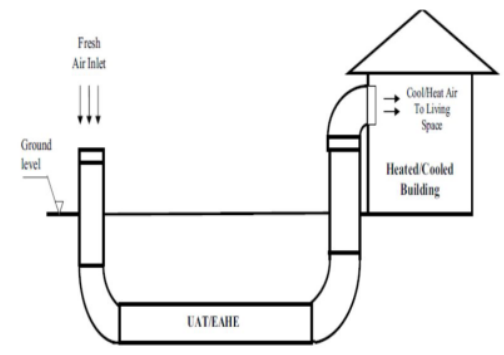

Fig. 1 Open Type Earth Air Tunnel Heat Exchanger [5]

\section{B. Closed system:}

In closed systems the heat exchangers are located underground, either in horizontal, vertical or oblique position, and a heat carrier medium is circulated within the heat exchanger, transferring the heat from the ground to a heat pump or vice versa. 
ELK Asia Pacific Journals - Special Issue
ISBN: 978-81-930411-4-7

which may hinder or preclude proper implementation include shallow bedrock, high water tables, and insufficient space, among others. In some areas only cooling or heating may be afforded by EATHE. In these areas, provision for thermal recharge of the ground must especially be considered.

\section{DESCRIPTION OF EATHE}

It is underground heat exchangers that can capture heat from or dissipate heat to the ground. They use the earths near constant subterranean temperature to warm or cool air or other fluids for residential, agricultural or industrial uses. Temperature difference between air and soil can be utilized to pre cool and pre heat ventilated air supply using EATHE in summer and winter respectively. An earth air heat exchanger consist of one or more tubes lied under the ground in order to cool in summer or pre-heat in winter, the air to be supplied in a building. The physical phenomenon of earth air heat exchanger is simple: the ground temperature commonly higher than the outdoor air temperature in winter and lower in summer, so it makes the use of the earth convenient as warm or cold sink respectively. Both of the above uses of earth air heat exchanger can contribute to reduction in energy consumption. Several researchers have described the earth-toair heat exchangers (EATHE) coupled with buildings as an effective passive energy source for building space conditioning. An earth-to-air heat exchanger system suitably meets heating and cooling energy loads of a building. Its performance is based upon the seasonally varying inlet temperature, and the tunnel-wall temperature which further depends on the ground temperature. The performance of an EATHE system depends upon the temperature and moisture distribution in the ground, as well as on the surface conditions. The principle of using ground inertia for heating and cooling is not a new concept, but rather a modified concept that goes back to the Ancients. This technology has been used throughout history from the ancient Greeks and Persians in the pre- Christian era until recent history (Santamouris and Asimakopoulos, 1996). For instance the Italians in the middle Ages used caves, called colvoli, to pre-cool/pre-heat the air before it entered the building. The system which is used nowadays consists of a matrix of buried pipes through which air is transported by a fan. In the summer the supply air to the building is cooled due to the fact that the ground temperature around the heat exchanger is lower than the ambient temperature. During the winter, when the ambient temperature is lower than the ground temperature the process is reversed and the air gets pre-heated.

\section{EXPERIMENTAL AND ANALYTICAL ANYLASIS}

An EATHE is an underground heat exchanger that can capture heat from and/ or dissipate heat to the ground. It is 


\section{ELK Asia Pacific Journals - Special Issue \\ ISBN: 978-81-930411-4-7}

used geothermal energy for many applications like agricultural or industrial uses, heat recovery ventilation, and alternate to conventional central heating or air conditioning. In this chapter research papers are considered for understanding the effect of different parameters under different conditions.

Jacovides et al. (1995) described a TRNSYS model for the simulation of earth tube systems (TRNSYS is a computer modeling tool). They did not discuss the general potential of earth tubes for cooling or heating. The model includes latent heat transfer phenomena between the air and the pipe, and models the moisture content of the air circulating in the pipe and moisture migration through the soil with a temperature and moisture gradient. In the case studied (which is mostly applicable to greenhouses), the earth-to-air heat exchanger is buried under the foundation of the building. Ground temperature is therefore a superposition of the soil temperature field due to surface ground temperature and the temperature field due to the pipes themselves. Limited validation of the model was provided, as the time period was short (two summer months) and relative humidity was not measured. Mihalakakouet et al. (1996) provided simulation data for an earth tube system in Dublin, Ireland, and study the influence of pipe length, pipe radius, air flow velocity, and soil depth. The data shown indicated that with a system featuring a $30 \mathrm{~m}$ long, $125 \mathrm{~mm}$ diameter tube buried $1.2 \mathrm{~m}$ underground, with air velocities of $8 \mathrm{~m} / \mathrm{s}$, one can expect a maximum rise of air temperature between 2.1 and $7.9^{\circ} \mathrm{C}$, depending upon the time of year. These values increase roughly by $1^{\circ} \mathrm{C}$ for each additional meter in depth, and by 0.5 to $0.9^{\circ} \mathrm{C}$ for each additional $20 \mathrm{~m}$ in length. Lower velocities increase the temperature rise, and so do smaller diameters. However there was no discussion about the global energy performance of the system, which should include the energy used to power the fans. Also, it doesn't either provide a summary of energy gains on a monthly basis. Gauthier et al. (1997) presented a fully transient three-dimensional heat transfer model of heat pipes. The model can handle multiple pipes, nonhomogeneous soil properties, transient boundary conditions, and evaporation and condensation in the pipes. The model was validated against data from an earth tube system installed in a commercial greenhouse in Canada (unfortunately, only 3 days of data is used, probably because the model is very computationally expensive). They concluded with a parametric study to quantify the effect of various system variables. Deglin et al. (1999) conducted a theoretical model, with a particular application to livestock buildings; validation using an experimental setup is detailed. Corrugated, nonperforated plastic pipes were used. Validation was done with one year of data for a system including $18 \mathrm{~m}$ long, corrugated PVC pipes with 3 different diameters $(250,315$ and $400 \mathrm{~mm})$, buried at three different depths $(1.50,2.25$ and $3.00 \mathrm{~m})$. The authors concluded that (1) soils saturated in water are better from a thermal point of view, (2) greater depths are preferable since they provide higher temperatures in winter and lower temperatures in summer, (3) smaller pipes are more thermally efficient, i.e. they result in a higher heat exchange per unit volume of air; however they cause greater pressure losses and require larger installations (4) lower fan speeds lead to higher efficiencies, and (5) $70 \%$ of the heat transfer occurs within the first $10 \mathrm{~m}$ of the pipe. Sawhney et al. (1999) described a recirculation underground system made with concrete pipes. The system is used to air-condition a building in a tropical climate. The pipes form a closed circuit. Metal wire mesh is used to prevent insects and foreign matter from entering. The system is designed to work both for cooling and heating. Only one month of monitoring (May) was done. Air from the house is cooled by around $1.5^{\circ} \mathrm{C}$ as it passes through the system. Temperature of air delivered by the system is fairly stable (around $27^{\circ} \mathrm{C},-13$ - which is the ground temperature for the location). Relative humidity is somewhat higher (5\%) than that of a non-conditioned room; that is, moisture is added as it is circulated through the tubes. Given that a 3 HP blower is used to circulate the air, the COP was found to be only 3.35.

Staahl (2002) focused on the quality of the air coming out of earth tubes, particularly related to the moisture content. The author noted that the material of the earth-tube wall is of great importance since it determines the moisture transfer: for example concrete will let the moisture through, plastic will not. For that reason the relative humidity predicted by the author for a concrete tube is $100 \%$ year round. For a plastic tube it reaches $100 \%$ only in summer in a Nordic climate. Over half the year the relative humidity is above $80 \%$, which is conducive to mold growth. He also mentioned mold growth in two of three Swedish schools equipped with earth tubes. On the energy side, the author predicted(through simulations) that an earth tube will typically deliver $1,200 \mathrm{kWh} / \mathrm{yr}$ to a house in the Swedish climate, or about $10 \%$ of the heating needs. Bansal et al. (2009) developed a mathematical modeling to investigate the potential of storage capacity of the ground for cooling with the help of an EATHE system integrated with evaporative cooler. From mathematical model they concluded that for a given diameter of pipe, volumetric flow rate set of inlet \&outlet temperature owing to coupling the evaporative cooler with EATHE, there is a decrease in the length of the buried pipe. This decrease is found to be in the range of 0.993.5\% of length. They also concluded the decrease in length also depends upon the bypass factor that decreases by 93.5 $22.9 \%$ when factor decreases from 0.2-0.5. Bansal et al. (2011) presented enhancement in the performance of simple EATHE by integrating an evaporative cooler at outlet. After experimentation the result showed that while ambient air itself is comfortable for 25.65 of the hours, use of integrated EATHE- evaporative cooling system provides comfortable air for $34.16 \%$ hours in one year; whereas simple EATHE is able to provide comfortable air only for $23.33 \%$ additional hours. They found that on annual basis the integrated EATHEevaporative cooling system delivers 4856 MJ of cooling effect, $4500 \mathrm{MJ}$ is achievable with simple EATHE system and 
ELK

Asia Pacific Journals

remaining 3190MJ is achieved due to integration of EATHE with evaporative cooling at its outlet. Bansal et al. (2012) made an attempt to enhance the performance of active cooling system by coupling it with EATHE in four different hybrid modes. In mode I air conditioner alone supplied the conditioned air to the room and EATHE is not functional. In mode II air conditioner supplies conditioned air to the room and $100 \%$ conditioned air from EATHE is also delivered directly to the room. Air conditioner supplies the conditioned air to room and $100 \%$ conditioned air from EATHE is used for cooling the condenser tubes of air conditioner during mode III. In mode IV air conditioner supplies the conditioned air to room and 50\% conditioned air from the EATHE is fed to the room directly and remaining $50 \%$ air is used for condenser cooling of air conditioner. After experimentation they have investigated the thermal performance of the developed $1.5 \mathrm{TR}$ window type air conditioner and found the power consumption to be reduced by $18.1 \%$ when cold air from EATHE is completely used for condenser cooling of the air conditioner.

\section{CONCLUSION}

The ground or earth acts as a very large store of heat energy. It can be used as a heat source in winter or a heat sink in summer. The ground can be used to moderate the temperature in buildings standing on it. A ground heat exchanger can be used to extract heat energy from the ground in winter season to transfer the heat into houses at the same time, it can be used to provide a very efficient mechanism for heat rejection from buildings, free of all carbon emissions on site. It can make use of solar energy stored in the ground to provide one of the most energy-efficient ways of heating or cooling houses. Most systems usually constructed from 4-24inch diameter, smooth walled, rigid or semi rigid plastic, plastic coated metal pipes or plastic pipes, buried 1.5 to $3 \mathrm{~m}$ underground where the ambient earth temperature is typically 10 to $23^{\circ} \mathrm{C}$. Ground temperature becomes more stable with depth. Smaller diameter tubes require more energy to move the air and have less contact surface area. Larger tubes permit a slower air flow, which yields more efficient energy transfer and permits much higher volumes to be transferred, permitting more air exchanges in a short every time period. Sharp $90^{\circ}$ angles should be avoided in the construction of the tube. Two $45^{\circ}$ bends produce less turbulent, more efficient air flow.

\section{REFERENCE}

[1] Bansal V., Misra R., Agrawal G.D., Mathur J., (2009) "a mathematical modeling to investigate the potential of storage capacity of the ground for cooling with the help of an EATHE system integrated with evaporative cooler”. Energy builds. Vol.42, pp. 645-8.

[2] Bansal V., Misra R., Agrawal G.D., Mathur J., (2011) “enhancement in the performance of simple EATHE by integrating an evaporative cooler at

\section{ELK Asia Pacific Journals - Special Issue \\ ISBN: 978-81-930411-4-7}

outlet". Energy builds. Vol.52, pp. 745-8.

[3] Bansal V., Misra R., Agrawal G.D., Mathur J., (2012) "enhance the performance of active cooling system by coupling it with EATHE in four different hybrid modes". Energy builds. Vol.42, pp. 645-9.

[4] Breesch H., Bossaer B., Janssens A.,(2005),"Passive cooling in a low energy office building”, Energy Build, Vol. (45),pp. 215-222.

[5] Dubey Manojkumar,, Bhagoria J.L., Atullanjewar ,(2013), "Earth Air Heat Exchanger in Parallel Connection", International Journal of Engineering Trends and Technology (IJETT), Vol.4, pp.2463-246

[6] Gauthier C., LacroixM.,Bernier H., (1997), “Numerical simulation of soil heat exchanger-storage systems for greenhouses",Renewable Energy, Vol. (36), pp. 125-129.

[7] Ghosal G., Argiriou A., Lykoudis S., Balaras C., Asimakopoulos D.,(2004), “ Experimental study of a earth to air heat exchanger coupled with a photovoltaic system", Journal of solar energy engineering, pp. 189195.

[8] Jacovides C .P., Mihalakakou G., (1995), “ An underground pipe system as an energy source for cooling/heating purposes",Energy conversion management, Vol. (3), pp. 1463-83

[9] Mihalakakou G., Lewis J. O.,Santamouris M., (1996) , “On the heating potential of buried pipes techniques - application in Ireland",Energy Buildings,pp. 103-117.

[10] Staahl F., (2002), “ Preheating of Supply Air through an Earth Tube System - Energy Demand and Moisture Consequences", energy build, pp. 315-318.

[11] Santamouris, G., Mihalakakou G., Balarar C.A.,(1995), "Use of buried pipes for energy conversation in cooling of agricultural greenhouses," Solar Energy, Vol. 55,pp. 111-124.

[12] Shukla Ashish,Tiwari G.N., Sodha M.S.,(2006), “Thermal modeling for greenhouse heating by using thermal curtain and an earth-air heat exchanger," Building and Environment, Vol. 41,pp.843-50.

[13 ] Sawhney R.L., Buddhi D.,Thanu N.M., (1999), “ An experimental study of summer performance of a recirculation type underground air pipe air conditioning system", Renewable energy, pp. 26-48. 